\title{
Naloxone can alter experimental pain and mood in humans
}

\author{
JONATHAN SCHULL and HILLARD KAPLAN \\ University of Pennsylvania, Philadelphia, Pennsylvania 19104 \\ and \\ CHARLES P. O'BRIEN \\ University of Pennsylvania, Philadelphia, Pennsylvania 19104 \\ and VA Medical Center, University and Woodland Avenues, Philadelphia, Pennsylvania 19104
}

\begin{abstract}
The present experiment investigated the possibility that endogenous opioids attenuate aversive experience in humans. Two experimental pain procedures-cold pressor pain, and ischemic pain produced by the submaximal effort tourniquet technique-were administered on each of 2 consecutive experimental days. Seven subjects received double-blind infusions of the opiate antagonist naloxone on Day 1 and saline on Day 2; for seven other subjects, the order was reversed. Based on earlier studies of exogenous opiate analgesics, the present experiment was designed to maximize subject anxiety and the "disturbingness" of the ischemic pain. Under these conditions, opiate receptor blockade significantly affected ratings and tolerance times for ischemic pain, anxiety, and mood. These results contrast with those of recent studies in which naloxone effects on experimental pain in humans were subtle or indiscernible, and suggest that psychological factors will have to be controlled and studied in the investigation of physiological bases of pain and other psychological states.
\end{abstract}

The discovery of endogenous opioid substances (endorphins) in animal nervous systems has spawned a series of experiments designed to explore their natural functions and the conditions under which they are active (Fanselow, in press; Maier, Drugan, Grau, Hyson, MacLennan, \& Moye, in press; Riley, Zellner, \& Duncan, 1980; Sherman \& Liebeskind, 1980; Snyder, 1980). Since exogenous opiates such as morphine have analgesic properties, it has been supposed that one natural function of endorphins is to modulate pain. If this is the case, naloxone, an opiate antagonist, should enhance pain by preventing endorphins from producing their effects. Clinical pain reportedly is enhanced by naloxone (Lasagna, 1965; Levine, Gordon, Jones, \& Fields, 1978; cf. Goldstein \& Grevert, 1978). However, previous laboratory investigations using naloxone have failed to show that opiate receptor blockade has any appre-

This study was conducted in the laboratories of the Drug Dependence Treatment and Research Service of the Philadelphia VA Medical Center, and was supported by USPHS Grants DA00586 and DA01218 and a VA Medical Research Grant to Charles O'Brien, by NSF Grant BNS 76-80108 to Paul Rozin, and by an NIH predoctoral fellowship, 5-F31-DA05132-02, to Jonathan Schull. For their assistance at various stages in this research project, we thank Doris Battle, Robert Greenstein, Priscilla Grevert, Ralph Lyons, Anthony Martinez, Sam Opaku, Martin Orne, Susan Ray, Anita Roselle, Paul Rozin, Richard Solomon, Joseph Ternes, S. Wallenstein, and George Woody. Address reprint requests to Jonathan Schull, Department of Psychology, Haverford College, Haverford, Pennsylvania 19041. ciable effects on experimental pain in humans (El-Sobky, Dostrovsky, \& Wall, 1976; Grevert \& Goldstein, 1977, 1978; Volavka, Bauman, Pevnick, Reber, James, \& Cho, 1980), although, in subgroups of subjects, interactions of naloxone with pain sensitivity (Buchsbaum, Davis, \& Bunney, 1977) and stress (Frid, Singer, \& Rana, 1979; Willer, Dehen, \& Cambier, 1981) have been reported. These largely negative results should not be discouraging, however, since even exogenous opiate analgesics, so effective in clinical situations, are notoriously variable in the laboratory (Adler \& Lomazzi, 1974; Beecher, 1959; Meyer, Greksch, \& Walther, 1978; Parry, 1979; Wolff, Hardy, \& Goodell, 1940). Until the factors which determine the effectiveness of opiates are brought under control, a clear test of the hypothesis that endogenous opiate systems function to reduce pain may be difficult to achieve. The purpose of the present experiment was to provide such a test.

We reasoned that successful demonstration of naloxone-induced hyperalgesia, like that of opiate analgesia, would depend upon the extent to which experimental procedures approximate clinical pain. Procedures such as the submaximum-effort tourniquet technique have been developed to stimulate the severity and duration of clinical pain (Smith, Lowenstein, Hubbard, \& Beecher, 1968). This procedure is one of two pain-induction techniques employed in the present experiment. 
However, regardless of the pain stimulus per se, anxiety levels are typically higher in clinical situations than in the laboratory, and pain is often evaluated differently in these two contexts (Beecher, 1959; Smith, Lowenstein, Hubbard, \& Beecher, 1968; Sternbach, 1968; Wolff, Hardy, \& Goodell, 1940). While clinical pain is often evaluated in terms of the suffering it engenders, experimental pain is often not disturbing, and subjects and experimenters often focus on sensory aspects of pain. Even in the laboratory, however, it has been shown that manipulation of anxiety levels influences emotional components of pain and that higher levels of anxiety render subjects more susceptible to opiate analgesics (Chapman \& Feather, 1973; Gracely, McGrath, \& Dubner, 1978; Hill, Belleville, \& Wikler, 1955; Hill, Kornetsky, Flanary, \& Wikler, 1951, 1952a). Therefore, our study was designed to maximize subject anxiety and the "disturbingness" of the experimental procedures. We also measured disturbingness, as well as the intensity of the pain, and included a measure of pain tolerance time, which is thought to be a particularly sensitive measure of the affective dimensions of pain and is often found to be more sensitive to the effects of analgesics (e.g., Chapman \& Feather, 1973; Wolff, 1978; Woolf, 1979). Thus, our experiment was designed to simulate the severity, duration, and anxiety normally associated with clinical pain, and to assay the effect of opiate receptor blockade on emotional as well as sensory dimensions of pain.

\section{METHODS}

\section{Subjects}

Our subjects $(\mathrm{N}=14)$ were male $(\mathrm{N}=6)$ and female $(\mathrm{N}=8)$ paid volunteers, aged 18-55 years with a median age of 21 .

\section{Procedure}

A complete description of the experimental protocol is available in Schull (1980/1981).

Two pain procedures were employed, cold water immersion of the hand and ischemia. In the cold pressor technique, the subject placed his left hand in a bath circulating cold water $\left(10^{\circ} \mathrm{C}\right)$ for $7 \mathrm{~min}$. In the submaximum-effort tourniquet technique, ischemic pain was produced by inflating a blood pressure cuff placed above the elbow of the left arm to $250 \mathrm{~mm} \mathrm{Hg}$ and having the subject squeeze an exerciser handle 30 times. Each ischemic trial lasted until the subject asked to have the cuff deflated (with a 20-min limit); a measure of time to pain tolerance was thus obtained. For the duration of each procedure, the subject rated the intensity and the disturbingness of the pain at 15 -sec intervals on scales from 0 to 100 (see caption of Figure 1).

The experiment was conducted on 4 consecutive days. During the first ("orientation") day, the subjects were told that the purpose of the experiment was to study the effects of naloxone on psychological reactions to the experimental stimuli (no mention was made of endorphins or of the anticipated direction of the naloxone effect). The subjects were also trained in the use of the pain-rating scales during a practice cold pressor trial. Since pilot work had indicated that the ischemic pain procedure was most stressful on the first trial, this procedure was described but not practiced on the orientation day, in order to maximize the novelty and aversiveness of this procedure on the experimental days (cf. Johnson, 1973). The sequence of events on the 2 ex- perimental days was as follows: (1) insert intravenous needle (IV), (2) administer Profile of Mood States (POMS) questionnaire, (3) administer Spielberger Anxiety State questionnaire, (4) cold pressor procedure, (5) administer postpain questionnaire, (6) repeat Spielberger Anxiety State questionnaire, (7) ischemic pain procedure, (8) readminister postpain (mood) questionnaire, (10) taste preference procedure (Schull, 1980/1981; Rozin, Ebert, \& Schull, Note 1). Double-blind infusions of saline or naloxone $(10 \mathrm{mg} / 70 \mathrm{~kg})$ were delivered unsignaled at the beginning of each pain procedure, $1 \mathrm{~min}$ $45 \mathrm{sec}$ after the ratings began. Prior to the experiment, the subjects had been assigned randomly to groups. Group Nal-Sal received naloxone on the first experimental day and saline on the second; for Group Sal-Nal, the order was reversed. On the final day of the experiment, the subjects were interviewed (still double-blind) about their experiences during the experiment.

In order to heighten subject anxiety, the following features were incorporated into the experimental procedure: (1) Following placement of the IV, the subject was alone for the duration of each session in a sound-attenuated experimental chamber equipped with video monitoring equipment. (2) Communication with the subject was formal, and verbal interaction was minimized through the use of tape-recorded instructions. No reassurance was given during insertion of the IV. (3) The blood pressure cuff was inflated and deflated remotely from outside the chamber. The last manipulation, along with the omission of a practice trial with the submaximum effort tourniquet technique, should specifically have increased the aversiveness of the ischemic procedure.

\section{RESULTS}

Naloxone had no effects on ratings of cold pressor pain; scores on both experimental days were strikingly similar (mean naloxone score $=26.48$; mean saline score $=26.83$, based on the mean of the last 7 of 14 pain-intensity ratings). In contrast, naloxone did increase the aversiveness of the ischemic pain. As shown in Figure 1, time to tolerance was significantly shorter, and pain ratings were substantially higher on naloxone days than on saline days. It is also apparent that naloxone did not differentially affect ratings of disturbingness. The pattern of results was, however, different for the two groups (see Figure 2). Whereas no significant differences between naloxone and saline day scores were found for Group Sal-Nal, pain ratings and tolerance times were significantly different for Group Nal-Sal on the two experimental days. These conclusions are based on within-subject paired comparisons (naloxone day scores vs. saline day scores). It is also possible to make unpaired between-group comparisons of tolerance times on Day 1, when half the subjects received naloxone and the other half received saline. However, because of high intersubject variability (tolerance times ranged from 60 to $1,200 \mathrm{sec}$ ), betweengroup differences were not significant, although they were substantial (mean tolerance time for subjects receiving naloxone $=537.8 \mathrm{sec}$; mean for subjects receiving saline $=786.4 \mathrm{sec}$, Figure $2 \mathrm{a}$ ). (Even if variability had not been high, other between-group comparisons would not be valid. Pain ratings at selected times cannot be compared, because these times are based on each individual's tolerance time and are different between groups. Tolerance times and 
ratings for the two groups on Day 2 cannot be validly compared, because each group was treated differently on Day 1.)

In addition, responses to the anxiety questionnaire administered prior to the first infusion on each experimental day indicated that subjects who had received naloxone on Day 1 began the second experi-

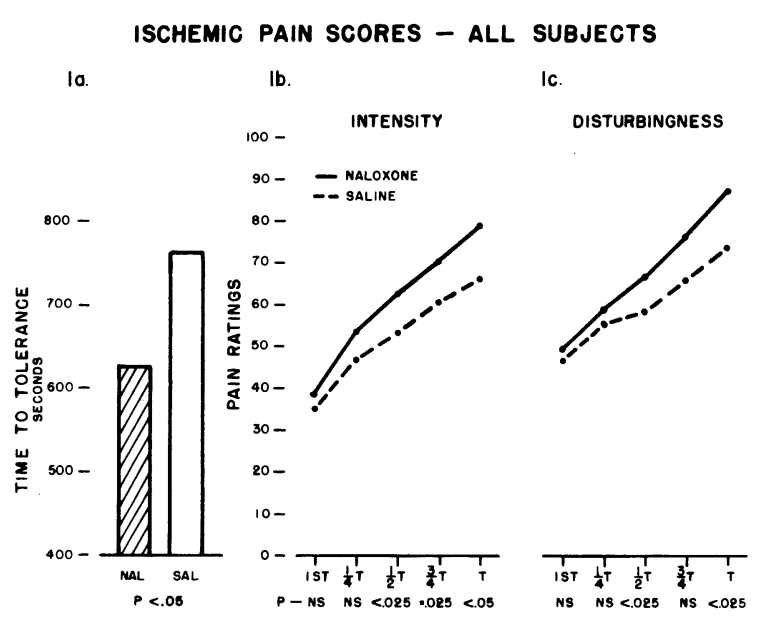

Figure 1. Mean scores for all subjects $(N=14)$ from the ischemic pain procedure. *Significant difference $(p<.05$, one-tailed), Wilcoxon matched pairs signed-ranks test. (1a) Time to tolerance on naloxone and saline days. (1b and 1c) Pain ratings at selected times based on each subject's time to tolerance ("T") on his shorter trial. The ratings were based on 100-point scales with the following descriptors: Intensity-10-weak, 30-moderate, 50-strong, 70-intense, 90-extremely intense. Disturbing-10-mild, 30discomforting, 50-distressing, 70-horrible, 90-excruciating, 100-unbearable.

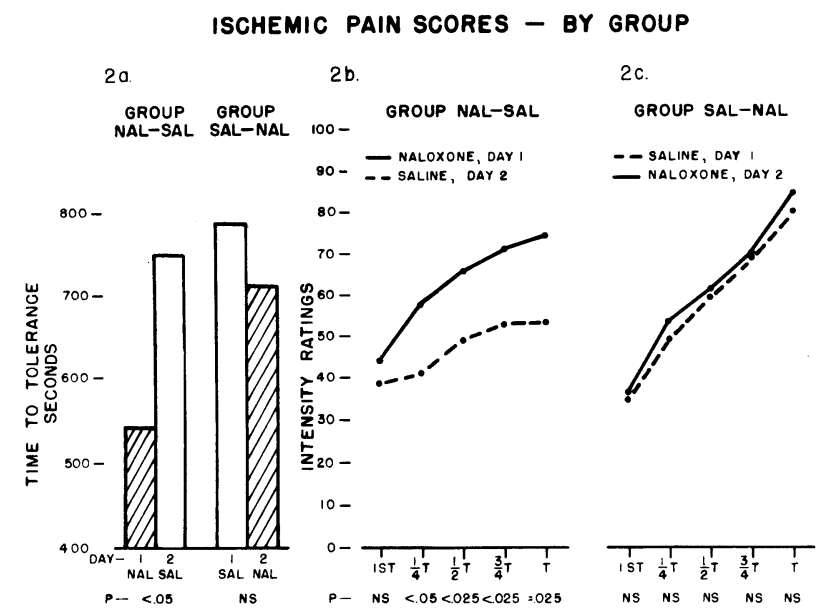

Figure 2. Comparison of Group Nal-Sal with Group Sal-Nal for ischemic pain scores. Significant between-day differences were obtained for Group Nal-Sal only $(p<.05$, Wilcoxon matchedpairs signed-ranks, one-tailed). (2a) Time to tolerance. (2b and $2 c$ ) Pain intensity ratings at selected times (see Figure 1). Similar results were obtained for disturbingness ratings (not shown). mental session with higher levels of anxiety than they had had at the beginning of the previous day, whereas subjects given saline infusions on Day 1 returned with reduced anxiety. These changes in initial anxiety levels were significantly different for the two groups ( $p<.05$, Mann-Whitney U, one-tailed), suggesting that naloxone prevented habituation to the experimental context, and/or enhanced the formation of a conditioned emotional response to situationai cues (cf. Ehrman, Josephson, Schull, \& Sparich, 1979, cited in Schull, 1979, pp. 75-77; Fanselow, in press). A similar pattern was seen in responses to the postpain questionnaire administered immediately following the ischemic trial. Subjects in both groups tended to report that their mood had gotten worse on naloxone days, and better on saline days. These differences in mood change were significant $(p<.01$, Wilcoxon matched-pairs, one-tailed) and again tended to be more pronounced in Group Nal-Sal. The Tension-Anxiety scale of the POMS yielded a related finding. From the beginning to the end of the saline sessions, both groups showed a large decrease in tension-anxiety, which differed significantly from the smaller decrease observed during naloxone sessions $(p<.05$, Mann-Whitney $U$, one-tailed). In fact, during the naloxone day, there was a small within-session increase in tension-anxiety for Group Nal-Sal. These results parallel Grevert and Goldstein's (1977) earlier findings, which they were subsequently unable to replicate (Grevert \& Goldstein, 1978). Finally, in the retrospective interviews, we asked subjects to compare their overall experiences on the 2 experimental days. Their responses indicated that the experience was worse on the naloxone day for every subject in Group Nal-Sal and for four of seven subjects in Group Sal-Nal ( $p<.05$, chi-square test).

\section{DISCUSSION}

All of the data indicate that the naloxone day was considerably more aversive than the saline day for subjects in Group Nal-Sal. On the naloxone day, the subjects rated ischemic pain as being more aversive and terminated the ischemic trial earlier; immediately afterwards, they reported that their mood had gotten worse, and their anxiety scores, in fact, failed to drop off. They returned on Day 2 with higher levels of anxiety than they had evinced on Day 1. And they unanimously judged the overall Day 1 experience to be worse than the Day 2 experience. In contrast, the ratings and tolerance times of subjects in Group Sal-Nal were comparable on the 2 experimental days. Over the course of the experimental sessions, changes in mood and in anxiety on the saline and naloxone days were more similar for Group Sal-Nal than they were for Group Nal-Sal. And, finally, the Sal$\mathrm{Nal}$ subjects were about as likely to deem the saline 
day as more aversive than the naloxone day, as vice versa.

It would be tempting to suggest, therefore, that, consistent with our intention of maximizing the novelty and aversiveness of the ischemic procedure on the first experimental day, naloxone had a larger effect on the group that received naloxone on that day. But this does not necessarily follow. Previous work has shown that the ischemia procedure tends to become less aversive with repeated exposure (e.g., Smith et al., 1968; Von Graffenreid, 1978); therefore, naloxone may have counteracted this tendency for Group Sal-Nal or exaggerated it for Group NalSal, or both. To decide which of these possibilities was the case, a saline-saline group would be required to assess habituation to the ischemia procedure in the experimental situation in the absence of naloxone. In any case, it is clear that naloxone did have a significant overall effect on ischemic pain ratings and tolerance times, and on anxiety and mood.

These results raise the following questions. Why was cold pressor pain unaffected by naloxone, and why have other studies failed to demonstrate naloxone effects on ischemic pain? One possibility is that the naloxone infusion was not administered early enough for it to have an effect on cold pressor pain. However, naloxone antagonism of morphine effects is pronounced within $30-60 \mathrm{sec}$; the last $6 \mathrm{~min}$ of cold pressor pain should therefore have been sufficient for detection of the naloxone effect. Another possibility is that the cold pressor pain "primed" the endorphin systems, rendering them sensitive to receptor blockade, as revealed in the subsequent ischemic trial. However, Frid and Singer's (1979) and Grevert and Goldstein's $(1977,1978)$ studies similarly primed their ischemic pain trials with an earlier ischemic trial, but this apparently did not enhance sensitivity to naloxone (cf. Willer, Dehen, \& Cambier, 1981). It is more likely that the quality, neural substrates, and/or aversiveness of the two pain procedures are importantly different. Subjects described cold pressor pain as sharp and intense, building rapidly for the first 60 to $90 \mathrm{sec}$ and then dropping off steadily thereafter. In contrast, the ischemic procedure was characterized as more disturbing than intense, producing a particularly unpleasant discoloration of the hand and a deep, dull ache which grew steadily worse as the trial progressed. Furthermore, unlike the cold pressor procedure that was practiced on the orientation day, the ischemic procedure was first experienced on Experimental Day 1, under considerably more anxiety-provoking conditions. Perhaps for all these reasons, the ischemic procedure was generally considered the more disturbing, and it may therefore have been more sensitive to opiate effects. The dual rating scales of intensity and disturbingness were intended to demon- strate that opiate receptor blockade had a differential effect on the disturbingness of pain, but this finding was not obtained. Further analysis of the data (Schull, 1980/1981) revealed that subjects' ratings of intensity and disturbingness did not vary independently. In previous demonstrations of differential effects of drugs on sensory vs. affective pain ratings (Gracely et al., 1978), only one set of verbal descriptors was employed in a given experiment; in the present experiment, subjects were asked to switch from one scale to the other every $15 \mathrm{sec}$. It may be that it is difficult for subjects to change their mental "set" in this way, especially when the effect of the experimental drug is to exacerbate rather than reduce negative affect. Alternatively, it may simply be that naloxone does not have differential effects on motivational-emotional components of pain in humans.

With regard to earlier findings that naloxone does not affect experimental pain in humans (El-Sobky et al., 1976; Grevert \& Goldstein, 1977, 1978; Volavka et al., 1980), we suspect that those studies may have yielded largely negative results because, in the absence of anxiety, experimental pain may be nonthreatening and nondisturbing. There may be little endorphin activity to block, and, even if blocked, opiates have relatively little effect upon pain that is not disturbing. The literature on pain, anxiety, and opiates provides some support for this interpretation. As mentioned earlier, it has been suggested that experimental pain, even when intense, is often less anxiety-provoking than pathological pain (Beecher, 1959; Smith et al., 1968; Sternbach, 1968; Wolff et al., 1940). It has also been suggested that uncontrolled variations in anxiety may be responsible for discrepant results in the experimental literature on pain and analgesia (Sternbach, 1968; Von Graffenreid et al., 1978). Anxiety is known to make experimental pain more aversive and more sensitive to opiate analgesia (Hill et al., 1951, 1952a, 1952b, 1955). Furthermore, anti-anxiety drugs have been shown to prolong tolerance times (Chapman et al., 1973) and to reduce affective, but not sensory, ratings of pain stimuli (Gracely et al., 1978; but cf. Gracely, Dubner, \& McGrath, 1979). The importance of such psychological factors in pain experiments agrees well with clinical reports. Patients with pathological pain often claim that morphine reduces the disturbingness of the pain (to which anxiety can be an important contributor) but not its intensity (Hardy,. Wolff, \& Goodell, 1952; Levine et al., 1978; Mansky, 1978), and morphine may be an effective anti-anxiety agent in its own right (Davis, 1979; Hill et al., 1955). It may therefore be that experimental pain must be sufficiently disturbing if it is to be sensitive to opiate effects.

There are also data suggesting that similar factors 
are important in understanding the activity of endogenous opioid systems. In humans, brainstimulation-induced analgesia (which appears to be mediated by endorphins) is greater for pathological pain than for experimental pain (Akil, Mayer, \& Liebeskind, 1976; Akil, Richardson, Hughes, \& Barchas, 1978; Hosobuchi, Adams, \& Linchitz, 1977; cf. Woolf, 1979). In animal studies, naloxone appears to have larger effects upon behaviors that reflect emotional rather than reflexive reactions to nociceptive stimulation (Amir \& Amit, 1978, 1979; Ehrman et al., cited in Schull, 1979). Moreover, it is possible that anxiety can stimulate endorphin activity: animal studies suggest that endogenous opioid systems can be activated by stress (Amir \& Amit, 1978; Bolles \& Fanselow, 1980; Maier et al., in press; Roth, Katz, Schmaltz, \& Sibel, 1981; Schull, 1979) and by fear (Bolles \& Fanselow, 1980; Fanselow, in press; Fanselow \& Bolles, 1979; Schull, 1979). The same may be true of humans (cf. Frid et al., 1979; Willer et al., 1981).

In the present experiment, the novelty of the ischemic pain tests on Day 1, our use of the tolerance procedure, the subject's expectation that the pain might at some point become "unbearable," the isolation of the subject in the experimental chamber, and the minimization and formalization of verbal interaction, may all have interacted critically with the endogenous opiate systems. Of course, this interpretation of our results must remain tentative until the anxiety hypothesis is directly tested in an experiment which manipulates levels of anxiety while assessing the effect of opiate receptor blockade. However, we suspect that the social and psychological conditions of pain perception play an important role in determining the organism's physiological responses to nociceptive and pharmacological stimuli. It may well be that even if one's goal is to understand the physiological mechanisms of pain and other psychological states, it will be necessary to investigate the sociopsychological conditions of their operation.

\section{REFERENCE NOTE}

1. Rozin, P., Ebert, L., \& Schull, J. The liking for chili pepper: A temporal analysis of the hedonic response. Manuscript submitted for publication.

\section{REFERENCES}

Adle R, R., \& Lomazzi, F. Mild analgesics evaluated with the submaximum effort tourniquet technique. Psychopharmacologia, 1974, 38, 351-362.

Akil, H., Mayer, D. J., \& Liebeskind, J. C. Antagonism of stimulation-produced analgesia by naloxone, a narcotic antagonist. Science, 1976, 189, 961-962.

Akil, H., Richardson, D. E., Hughes, J., \& Barchas, J. D. Enkephalin-like material elevated in ventricular cerebrospinal fluid of pain patients after analgetic focal stimulation. Science, 1978, 201, 463-465.

Amir, S., \& Aмıт, Z. The pituitary gland mediates acute and chronic pain responsiveness in stressed and non-stressed rats. Life Sciences, 1979, 24, 439-448.

Amir, S., \& Amiт, Z. Endogenous opioid ligands may mediate stress-induced changes in the affective properties of pain behavior in rats. Life Sciences, 1978, 23, 1143-1152.

BEECHER, H. K. Measurement of subjective responses. New York: Oxford University Press, 1959.

Bolles, R. C., \& Fanselow, M. S. A perceptual-defensiverecuperative model of fear and pain. Behavioral and Brain Sciences, 1980, 3, 121-131.

Buchsbaum, M. D., Davis, G. C., \& Bunney, W. E., Jr. Naloxone alters pain perception and somatosensory evoked potentials in normal subjects. Nature, 1977, 270, 620-622.

Chapman, C. R., \& Feather, W. Effects of diazepam on human pain tolerance and pain sensitivity. Psychosomatic Medicine, 1973, 35, 330-339.

Davis, G. C., Buchsbaum, M. D., \& Bunney, W. F., Jr. Naloxone decreases diurnal variation in pain sensitivity and somatosensory evoked potentials. Life Sciences, 1978, 23, 1449-1460.

DAvis, M. Morphine and naloxone: Effects on conditioned fear as measured with the potentiated startle paradigm. European Journal of Pharmacology, 1979, 54, 341-347.

EL-Sobky, A., Dostrovsky, J. O., \& Wall, P. D. Lack of effect of naloxone on pain perception in humans. Nature, 1976, 263, 783-784.

Fanselow, M. S. Naloxone and Pavlovian fear conditioning. Learning and Motivation, in press.

Fanselow, M. S., \& Bolles, R. C. Naloxone and shock-elicited freezing in the rat. Journal of Comparative and Physiological Psychology, 1979, 93, 736-744.

Frid, M., Singer, G., \& RANA, C. Interactions between personal expectations and naloxone: Effects on tolerance to ischemic pain. Psychopharmacology, 1979, 65, 225-231.

A. Goldstein, \& Grevert, P. Placebo analgesia, endorphins, and naloxone. Lancet, 1978, 654, 1385.

Gracely, R. H., McGrath, P., \& Dubner, R. Validity and sensitivity of ratio scales of sensory and affective pain descriptors: Manipulation of affect by diazepam. Pain, 1978, 5, 19-29.

Gracely, R. H., Dubner, R., \& McGrath, P. A. Narcotic analgesia: Fentanyl reduces the intensity but not the unpleasantness of painful tooth pulp sensation. Science, 1979, 203, 12611263.

Grevert, P., \& Goldstein, A. Effects of naloxone on experimentally induced ischemic pain and on mood in humans. Proceedings of the National Academy of Science U.S.A., 1977, 74, 1291-1294.

Grevert, P., \& Goldste in, A. Endorphins: Naloxone fails to alter experimental pain or mood in humans. Science, 1978, 199, 1093-1095.

Hardy, J. D., WolfF, H. G., \& Goodell, H. Pain sensations and reactions. Baltimore: Williams and Wilkins, 1952.

Hill, H. E., Belleville, R. E., \& Wikler, A. Studies on anxiety associated with anticipation of pain. Archives of Neurological Psychiatry, 1955, 73, 602.

Hill, H. E., Kornetsky, C. H., Flanary, H. G., \& Wikler, A. Effects of anxiety and morphine on discrimination of painful stimuli. Federation Proceedings, 1951, 10, 309.

Hill, H. E., Kornetsky, C. H., Flanary, H. G., \& Wikler, A. Studies on anxiety associated with anticipation of pain: I. Effect of morphine. AMA Archives of Neurology and Psychiatry, 1952, 67, 612-619. (a)

Hill, H. E., Kornetsky, C. H., Flanary, H. G., \& Wikler, A. Effects of anxiety and morphine on discrimination of intensities of painful stimuli. Journal of Clinical Investigation, 1952, 31, 473-480. (b) 
Hosobuchi, Y., Adams, J. E., \& Linchitz, R. Pain relief by electrical stimulation of the central gray matter in humans and its reversal by naloxone. Science, 1977, 197, 183-185.

Johnson, J. E. Effects of accurate expectations about sensations on the sensations on the sensory and distress components of pain. Journal of Personality and Social Psychology, 1973, 27, 261-275.

LASAGNA, L. Naloxone hyperalgesia in post operative patients. Proceedings of the Royal Society of Medicine, 1965, 58, 978-983.

Levine, J. D., Gordon, N. C., Jones, R. T., \& Fieidd, H. L. The narcotic antagonist naloxone enhances clinical pain. Nature, 1978, 272, 826-827.

Maier, S. F., Drugan, R., Grau, J. W., Hyson, R., MacLennan, J. A., Moye, T., Madden, J., IV, \& Barchas, J. D. Learned helplessness, pain inhibition, and the endogenous opiates. In M. D. Zeiler \& P. Harzem (Eds.), Advances in analysis of behavior (Vol. 4). New York: Wiley, in press.

Mansky, P. A. Opiates: Human psychopharmacology. In L. L. Iversen, S. D. Iversen, \& S. H. Snyder (Eds.), Handbook of psychopharmacology (Vol. 12): Drugs of abuse. New York: Plenum, 1978.

Meyer, F. P., Greksch, G., \& Walther, H. Effectiveness of analgesics evaluated with the tourniquet technique. International Journal of Clinical Pharmacology, 1978, 16, 229-234.

PARRY, W. L. The evaluation of analgesic drugs: The case for experimental methods. Anesthesia, 1979, 34, 468-475.

Riley, A. L., Zellner, D. A., \& Duncan, H. J. The role of endorphins in animal learning and behavior. Neuroscience and Biobehavioral Reviews, 1980, 4, 69-76.

Roth, K. A., Katz, R. J., Schmaltz, K., \& Sibel, M. Reduced behavioral activity due to opiate blockade: Relations to stress. International Journal of Neuroscience, 1981, 12, 59-62.

Schull, J. A conditioned opponent theory of Pavlovian conditioning and habituation. In G. Bower (Ed.), The psychology of learning and motivation. New York: Academic Press, 1979.

Schull, J. Pain, pleasure, and the effects of opiate receptor blockade in humans. (Doctoral dissertation, University of Pennsylvania, 1980). Dissertation Abstracts International, 1981, 41, 4300B. (University Microfilms No. 8107798)

Sherman, J. E., \& Liebeskind, J. C. An endorphinergic, centrifugal substrate of pain modulation: Recent findings, current concepts and complexities. In J. J. Bonica (Ed.), Pain. New York: Raven Press, 1980.

Smith, G. M., Lowenstein, E., Hubbard, J. H., \& Beecher, H. K. Experimental pain produced by the submaximum effort tourniquet technique: Further evidence of validity. Journal of Pharmacology and Experimental Therapeutics, 1968, 163, 468-474.

SNYDER, S. H. Brain peptides as neurotransmitters. Science, 1980, 209, 976-983.

Sternbach, R. Pain: A psychophysiological analysis. New York: Academic Press, 1968.

Volavka, J., Bauman, J., Pevnick, J., Reber, D., James, B., \& CHо, D. Short-term hormonal effects of naloxone in man. Psychoneuroendocrinology, 1980, 5, 225-234.

Von Graffenreid, B., Adler, R., Abt, K., Nuesch, E., \& SPIEGEL, R. The influence of anxiety and pain sensitivity on experimental pain in man. Pain, 1978, 4, 253-263.

Willer, J. C., Dehen, H., \& Cambier, J. Stress-induced analgesia in humans: Endogenous opioids and naloxone-reversible depression of pain reflexes. Science, 1981, 212, 689-691.

WolfF, B. B. Behavioral measurement of human pain. In R. A. Sternbach (Ed.), The psychology of pain. New York: Raven Press, 1978.

Wolff, B. B., Kantor, T. G., Murray, M. D., Jarvick, M. E., \& LASKA, E. Response of experimental pain to analgesic drugs: 1. Morphine, aspirin and placebo. Clinical Pharmacology and Therapeutics, 1966, 7, 224-238.

WolfF, H. G., HaRdy, J. D., \& Goodell, H. Studies on pain: Measurement of the effect of morphine, codeine and other opiates on the pain threshold and an analysis of their relation to the pain experience. Journal of Clinical Investigation, 1940, $19,659-680$.

Woolf, C. J. Transcutaneous electrical nerve stimulation and the reaction to experimental pain in human subjects. Pain, 1979, 7, 115-127.

(Manuscript received June 12, 1981; revision accepted for publication August 10, 1981.) 